\title{
PERANAN RUMAH SINGGAH AL MAUN DALAM MEMBERIKAN PENDAMPINGAN ANAK TERLANTAR DI KOTA BENGKULU
}

\author{
Hendi Sastra Putra \\ Lembaga Konsultasi Dan Bantuan Hukum Universitas Muhammadiyah Bengkulu \\ Jalan Bali, Kampung Bali, Kecamatan Teluk Segara, Kota Bengkulu, Bengkulu \\ Email: Hendi.S.Putra@yahoo.co.id
}

\begin{abstract}
The most disadvantaged child is a child chosen 5-18 years due to a certain cause (due to several groups: poverty, one of the parents / guardian who is sick, one / both parents / guardian), the family is not harmonious, there is no caregiver) so it cannot fulfill basic needs physically, spiritually, or socially. In the city of Bengkulu at the present time every meeting involving children is scheduled between 5-18 years and the children are busking and asking for mercy by two-wheeled or four-wheeled motorists. Pay attention to the attention of the Bengkulu city government in handling and providing assistance to the outermost child so that in this case the bBengkulu provincial government has overcome the 1945 Constitution. Hoping the government has responsibility for the care and guidance of abandoned children. How is the concept of al-maul shelter in providing assistance to neglected children in the city of Bengkulu. to find out the role of open houses in providing assistance for abandoned children in the city of Bengkulu. Empirical Law Research is a legal research method that uses empirical facts derived from human behavior, both verbal policies obtained from interviews and research conducted through direct search. Primary data is data obtained directly from the field based on respondents and informants. Secondary data is obtained from literature books, regulations, internet browsing, and other documents. Work program stopover al maun is, access to fulfillment of children's identity, access to basic education and character of children, access to health training, skills training, development of children's interests and talents, increasing family capacity, building networks with various related parties.
\end{abstract}

Keywords: Neglected Children; Al Maun Shelter; Work program;

\begin{abstract}
Abstrak: Anak terlantara adalah anak yang berusia 5-18 tahun yang karena sebab tertentu (karena beberapa kemungkinan: kemiskinan, salah seorang dari orang tua/wali sakit, salah seorang/kedua orang tua/wali pengasuh meninggal, keluarga tidak harmonis, tidak ada pengasuh) sehingga tidak dapat terpenuhinya kebutuhan dasar dengan wajar baik jasmani, rohani, maupun sosial. Di kota Bengkulu pada saat sekarang ini setiap persimpangan terdapat anak-anak yang berusia antara 5-18 tahun dan anak-anak tersebut mengamen dan mengharapkan belas kasihan oleh pengendara roda dua maupun roda empat. Kurangnya perhatian dari pemerintah kota bengkulu dalam menanggani dan melakukan pendampingan terhadap anak terlanta sehingga dalam hal ini pemerintah provinsi bengkulu telah melanggar UUD 1945. Memberikan perlindungan yang sudah diatur dalam UUD NKRI tahu 1945 Pasal 34 ayat (1) bahwa "Fakir miskin dan anak terlantar dipelihara oleh negara". Artinya pemerintah mempunyai tanggung jawab terhadap pemeliharaan dan Pembinaan anak terlantar. Bagaimana konsep rumah singgah al-maul dalam memberikan pendampingan anak terlantar di kota bengkulu. untuk mengetahui Peranan rumah singgah al maun dalam memberikan pendampingan anak terlantar di Kota Bengkulu. Penelitian Hukum Empiris adalah suatu metode penelitian hukum yang menggunakan fakta-fakta empiris yang diambil dari perilaku manusia, baik perilaku verbal yang didapat dari wawancara maupun perilaku nyata yang dilakukan melalui pengamatan langsung. Data primer merupakan data yang diperoleh secara langsung dari lapangan berdasarkan dari responden dan narasumber. Data sekunder Data-data tersebut diperoleh dari buku-buku kepustakaan, peraturan perundang-undangan, browsing internet, dan dokumen-dokumen lainnya. Program kerja sumah singgah al maun adalah, Akses pemenuhan identitas anak, Akses pendidikan dasar dan karakter anak, Akses pelayanan kesehatan, Pelatihan keterampilan, Pengembangan minat dan bakat anak, Peningkatan Kapasitas Keluarga, Membangun jejaring dengan pihak terkait.
\end{abstract}

Kata kunci: Anak Terlantar; Rumah Singgah Al Maun; Program kerja; 



\section{Pendahuluan}

Di dalam Ketetapan MPR No. II/MPR/1983 dalam Agung Wahyono dan Siti Rahayu (1993:1), Pembangunan Manusia Indonesia seutuhnya. ${ }^{1}$. Ini berarti bahwa pembangunan tidak hanya mengejar kemajuan lahiriah seperti pangan, sandang, perumahan, kesehatan dan sebaganya. Atau kepuasaan batiniah seperti pendidikan, rasa aman, bebas mengeluarkan pendapat yang bertanggung jawab, rasa keadilan dan seterusnya, melainkan keselarasan/keserasian dan kesimbangan antara keduanya.

Pembangunan nasional yang merupakan proses modernisasi membawa dampak positif maupun negatif. Banyak peristiwa yang menarik perhatian masyarakat akhir-akhir ini yaitu dengan semakin banyaknya perbuatanperbuatan pidana/kejahatan, delikuensi/kenakalan anak-anak atau meningkatnya deviasi serta anak-anak terlantar.

Kejahatan atau tindak kriminil merupakan salah satu bentuk dari perilaku menyimpang yang selalu ada dan selalu melekat pada tiap bentuk masyarakat, tidak ada masyarakat yang sepi dari kejahatan.

Menurut Saparinah Sadli dalam Muladi dan Barda Nawawi (1998:148), "perilaku menyimpang itu merupakan suatu ancaman yang nyata atau ancaman terhadap normanorma sosial yang mendasari kehidupan atau

1 Agung Wahyono\& siti Rahayu, 1993, Tinjauan Tentang Peradilan Anak di Indonesia, Jakarta, Sinar Garfika. h. 12 21 keteraturan sosial, dapat , menimbulkan ketegangan individual maupun keteganganketegangan sosial, dan merupakan ancaman riil atau potensiil bagi berlangsungnya ketertiban sosial ${ }^{2}$.

Anak menurut bahasa adalah keturunan kedua sebagai hasil antara hubungan pria dan wanita. Dalam konsideran Undang-Undang No. 23 Tahun 2002 tentang perlindungan anak, dikatakan bahwa anak adalah amanah dan karuni Tuhan Yang Maha Esa, yang dalam dirinya melekat harkat dan martabat sebagai manusia seutuhnya ${ }^{3}$.

Anak terlantar adalah anak yang karena suatu sebab orang tuanya melalaikan dan atau tidak mampu melaksanakan kewajibannya sehingga kebutuhan anak baik jasmani, rohani maupun sosialnya tidak terpenuhi ${ }^{4}$.

Anak terlantara adalah anak yang berusia 5-18 tahun yang karena sebab tertentu (karena beberapa kemungkinan: kemiskinan, salah seorang dari orang tua/wali sakit, salah seorang/kedua orang tua/wali pengasuh meninggal, keluarga tidak harmonis, tidak ada pengasuh) sehingga tidak dapat terpenuhinya kebutuhan dasar dengan wajar baik jasmani, rohani, maupun sosial ${ }^{5}$.

Anak Terlantar adalah anak karena suatu sebab orangtuanya melalaikan kewajibannya

\footnotetext{
${ }^{2}$ Muladi \& Barda Nawawi, 1998 Teori-teori dan Kebijakan Pidana. Bandung, P.T Alumni.

3 M. Nasir Djamil, Anak Bukan Untuk Dihukum, Sinar Grafika, Jakarta, 2013, hlm. 8

${ }^{4}$ https://kurniawanramsen.blogspot.com/2013/0 6/definisi-anak-terlantar.html

${ }^{5}$ https://kurniawanramsen.blogspot.com/2013/0 6/definisi-anak-terlantar.html
} 
sehingga kebutuhan anak tidak dapat terpenuhi dengan wajar baik secara rohani, jasmani dan sosial yang dimaksud anak terlantar adalah anak yang tinggaldalam keluarga miskin usia sampai dengan 18 tahun $^{6}$.

Di kota Bengkulu pada saat sekarang ini setiap persimpangan terdapat anak-anak yang berusia antara 5-18 tahun dan anak-anak tersebut mengamen dan mengharapkan belas kasihan oleh pengendara roda dua maupun roda empat. Kurangnya perhatian dari pemerintah kota bengkulu dalam menanggani dan melakukan pendampingan terhadap anak terlanta sehingga dalam hal ini pemerintah provinsi bengkulu telah melanggar UUD 1945. Memberikan perlindungan yang sudah diatur dalam UUD NKRI tahu 1945 Pasal 34 ayat (1) bahwa "Fakir miskin dan anak terlantar dipelihara oleh negara”. Artinya pemerintah mempunyai tanggung jawab terhadap pemeliharaan dan Pembinaan anak terlantar.

Perlindungan anak merupakan suatu usaha untuk mewujudkan keadilan dalam suatu masyarakat, dengan demikian maka perlindungan anak harus diusahakan dalam berbagai bidang kehidupan bernegara dan bermasyarakat. Perlindungan anak bertujuan untuk menjamin terpenuhinya hak-hak anak agar dapat hidup, tumbuh, berkembang dan berpartisipasi secara optimal sesuai dengan harkat da nmartabat kemanusiaan, serta mendapat perlindungan dari kekerasan,

\footnotetext{
${ }^{6} \mathrm{https}: / /$ kurniawanramsen.blogspot.com/2013/0 6/definisi-anak-terlantar.html
}

diskriminasi, perlakuan salah, eksploitasi, dan penelantaran secara sistematis, terintegrasi dan berkesinambungan.

Muhammadiyah sebagai salah satu organisasi islam terbesar di Indonesia dan tersebar di berbagai Provinsi di Indonesia khususnya Provinsi Bengkulu telah mendirikan amal usaha muhammadiyah yaitu AL-MAUN yang menyediakan wadah penampungan dan pelatihan bagi anak terlantar di kota bengkulu.

Berdasarkan hal latar belakang tersebut peneliti tertarik meneliti mengenai anak terlantar dengan judul "PERANAN RUMAH SINGGAH AL MAUN DALAM MEMBERIKAN PENDAMPINGAN ANAK TERLANTAR DI KOTA BENGKULU"

\section{A. Permasalahan}

Bagaimana konsep rumah singgah al-maul dalam memberikan pendampingan anak terlantar di kota bengkulu.

\section{B. Tujuan dan Kegunaan Penelitian}

\section{Tujuan Penelitian}

Berdasarkan rumusan masalah diatas, maka tujuan penelitian ini adalah untuk mengetahui Peranan rumah singgah al maun dalam memberikan pendampingan anak terlantar di Kota Bengkulu.

\section{Kegunaan Penelitian}

Kegunaan penelitian ini nantinya dapat digunakan sebagai data awal bagi 
AL-IMARAH: Jurnal Pemerintahan dan Politik Islam Vol. 5, No. 1, 2020

pemerintah dalam memberikan pendampingan bagi anak terlantar di kota Bengkulu.

\section{Metode Penelitian}

\section{Jenis Penelitian}

Penelitian Hukum Empiris adalah suatu metode penelitian hukum yang menggunakan faktafakta empiris yang diambil dari perilaku manusia, baik perilaku verbal yang didapat dari wawancara maupun perilaku nyata yang dilakukan melalui pengamatan langsung. Penelitian empiris juga digunakan untuk mengamati hasil dari perilaku manusia yang berupa peninggalan fisik maupun $\operatorname{arsip}^{7}$

\section{Data Penelitian}

Penelitian ini menggunakan data primer dan data sekunder, yaitu :

\section{a. Data Primer}

Data primer merupakan data yang diperoleh secara langsung dari lapangan berdasarkan dari responden dan narasumber. Pengumpulan data dilapangan yang dilakukan oleh peneliti dengan cara wawancara

\section{b. Data Sekunder}

Pengumpulan data dalam studi pustaka ini dilakukan penelitian

${ }^{7}$ Mukti Fajardan Yulianto Achmad, 2010, Dualisme Penelitian Hukum Empiris \& Normatif, PustakaPelajar, h.280 dengan cara mempelajari dan mengumpulkan data yang berhubungan dengan objek penelitian. Data-data tersebut diperoleh dari buku-buku kepustakaan, peraturan perundang-undangan, browsing internet, dan dokumen-dokumen lainnya. Dalam hal ini peneliti mencari buku-buku yang dibutuhkan.

Data hukum sekunder terdiri dari 3 jenis bahan hukum, yaitu :

\section{Bahan hukum Primer}

Bahan hukum primer adalah bahan hukum yang mengika tatau bahan yang berkai terat dengan permasalahan yang diteliti.

\section{Bahan Hukum Sekunder}

Bahan hukum yang memberikan penjelasan terhadap/mengenai bahan hukum primer, seperti, doktrin, hasil penelitian dan karya ilmiah

\section{Bahan HukumTersier}

Bahan yang memberikan petunjuk dan penjelasan terhadap bahan hukum primer dan bahan hukum sekunder yaitu berupa kamus umum, kamus hukum, majalah dan ensiklopedia di bidang hukum

\section{Analisis Data}

Data yang telah dikumpulkan dalm pencarian data itu disusun dalam satu sistem (disistematisir), kemudian data yang telah 
tersusun dalam satu sistem itu dijelaskan dalam satu evalusai, selanjutnya berdasarkan penjelasan dan evaluasi dibuat kesimpulan ${ }^{8}$. Pengolahan data pada penelitian hukum pada intinya adalah mencari kebenaran hukum, kebenaran hukum adalah kebenaran dalam arti suatu kesesuaian dengan hukum positif dan kebenaran hukum positif.

Kebenaran kualitatif adalah kebenaran dalam arti kesesuaian dengan ukuran yang menetapkan persyaratan kualitas tertentu yang harus dipenuhi hal ini disebabkan karena kebenaran berdasarkan ketentuan hukum positif kebanyakan ditentukan berdasarkan persyaratan kualitas ${ }^{9}$.

Pengambilan kesimpulan dilakukan dengan :

a. Metode Deduktif yaitu dengan cara pengambilan kesimpulan dengan berpijak pada keterangan-keterangan yang bersifat umum. Dari keteranganketerangan tersebut ditarik kesimpulan yang bersifat khusus.

b. Metode Induktif yaitu dengan cara pengambilan kesimpulan dengan mendasarkan pada keteranganketerangan yang bersifat khusus. Dari keterangan-keterangan yang bersifat khusus tersebut kemudian ditarik kesimpulan yang bersifat umum.

${ }^{8}$ F Sugeng Istanto, 2007, Penelitian Hukum, CV. Ganda, Yogyakarta. h 26

${ }^{9}$ Ibid h. 60

\section{Tinjauan Teoritis}

\section{Pengertian Anak}

Pengertian anak menurut Kamus Besar Bahasa Indonesia adalah keturuan kedua dan atau manusia yang masih kecil. Menurut R.A. Kosnan "Anak-anak yaitu manusia muda dalam umur muda dalam jiwa dan perjalanan hidupnya karena mudah terpengaruh untuk keadaan sekitarnya"10.

Anak dalam Pasal.1 angka 5, UU Pemberantasan Tindak Pidana Perdagangan Orang, anak yang belum berusia 18 tahun.

Pengertian anak menurut KUHPerdata adalah dalam pasal 330 KUHPerdata anak adalah "Belum dewasa adalah mereka yang belum mencapai umur genap dua puluh satu tahun, dan lebih dahulu telah kawin." Disini artinya dewasa adalah ketika seseorang telah berusia dua puluh satu tahun penuh atau sudah menikah.

Undang-undang Nomor 4 tahun 1979 tentang kesejahteraan anak, pasal 1 angka 2 memberikan pengertian anak adalah seseorang yang belum mencapai umur 21 tahun dan belum pernah kawin. Dalam penjelasannya batas 21 tahun tahun ditetapkan oleh karena berdasarkan pertimbanan kepentingan

10 R.A. Koesnan, Susunan Pidana dalam Negara Sosialis Indonesia, (Bandung :Sumur, 2005), h. 113 
usaha kesejahteraan social, tahap kematangan social, kematangan pribadi dan kematangan mental seorang anak dicapai pada umur tersebut.

Pasal 1 angka 6 memberikan pengertian anak tidak mampu yaitu anak karena suatu sebab tidak dapat terpenuhi kebutuhan-kebutuhannya baik secara rohani, jasmani, maupun sosial dengan wajar

Anak menurut Wikipedia adalah anak (jamak:anak-ana) adalah seorang lelaki atau perempuan yang belum dewasa atau belum mengalami masa pubertas.

\section{Pengertian Anak Terlantar}

Anak terlantara dalah Anak Terlantar adalah anak karena suatu sebab orangtuanya melalaikan kewajibannya sehingga kebutuhan anak tidak dapat terpenuhi dengan wajar baik secara rohani, jasmani dan sosial yang dimaksud anak terlantar adalah anak yang tinggal dalam keluarga miskin usia sampai dengan 18 tahun $^{11}$.

Pasal 1 angka 7 memberikan pengertian mengenai anak terlantar yaitu : anak yang karena suatu sebab orang tuanya melalaikan kewajibannya sehingga kebutuhan anak tidak dapat terpenuhi dengan wajar baik secara rohani, jasmani maupun social dengan wajar.

\section{Pengertian Pendampingan}

Pengertian pendampingan menurut KBBI adalah proses, cara, perbuatan mendampingi atau mendampingkan;

Pengertian Pendampingan atau lebih dikenal dengan istilah Mentorship. Mentoring biasanya melibatkan bimbingan dari seorang individu yang lebih berpengalaman atau senior, mentoring menimbulkan hubungan pendampingan jangka panjang antara mentee dan mentor, mentor akan diharapkan untuk mengetahui jawaban atas tugas yang dilakukan oleh mentee ${ }^{12}$.

\section{Pembahasan}

\section{Konsep rumah singgah al-maul dalam memberikan pendampingan anak terlantar di kota bengkulu.}

$$
\text { Rumah singgah Al - Maun }
$$
merupakan sebuah lembaga pembinaan dan pendampingan anak-anak dhuafa terkhusus anak-anak jalanan di sekitar kota Bengkulu. Lembaga Al - Maun berdiri berdasarkan SK Pimpinan Wilayah Muhammadiyah Bengkulu pada 30 Januari 2016. Namun sebelumnya sudah mulai dirintis sejak september 2015 yang bermula dari kegiatan jumat berbagi yang

\footnotetext{
${ }^{11}$ https://kurniawanramsen.blogspot.com/2013/ 
merupakan kegiatan makan siang kepada kaum dhuafa yang disponsori oleh bebek manter dan bekerja sama dengan Lazismu PWM Bengkulu. Sejak 3 tahun berdirinya al maun, lembaga ini sendiir telah berpindah tempat mulai dari taman telkom, masjid Muhammadiyah Suprapto hingga pada akhirnya pada bulan april 2019 rumah singgah al maun mendapatkan hibah pakai berupa rumah kosong milik Universitas Muhammadiyah Bengkulu. Rumah ini memiliki 4 kamar tidur dan ruang tengah yang luas sehingga rumah ini dijadikan tempat anak-anak melakukan kegiatan rutin dan sekaligus juga tempat peristirahatan bagi anak-anak yang selama ini tidur di simpang lima taman telkom.

$$
\text { Walaupun masih banyak }
$$
kekurangan secara fisik mulai dari atap yang sudah lapuk dan bocor disana sini, belum tersedianya jaringan listrik dan air. Namun kegiatan pembinaan tetap berjalan walau dengan keterbatasn yang ada. Mimpi besar bagi pengurus rumah singgah al maun adalah naik kelas dalam hal pembinaan dan pendampingan, agar lebih intensif lagi dan berharap kedepan rumah singgah al maun menjelma menjadi pesantren bagi anak-anak dhuafa khususny anak jalanan.

Program Kerja Rumah Singgah Al Maun adalah :
1. Akses pemenuhan identitas anak

2. Akses pendidikan dasar dan karakter anak

3. Akses pelayanan kesehatan

4. Pelatihan keterampilan

5. Pengembangan minat dan bakat anak

6. Peningkatan Kapasitas Keluarga

7. Membangun jejaring dengan pihak terkait

Rumah singgah al maun setiap hari jumat ada agenda rutin setiap sore yang dibantu oleh relawan mahasiswa UMB dan kesejahteraan sosial UNIB yang di isi dengan kegiatan belajar baca Al-Quran, belajar bahasa inggris, pengetahuan umum, pendidikan karakter, dan keterampilan.

Tujuan pembinaan rumah singgah al maun adalah diharapkan dapat mengubah perilaku anak menjadi lebih santun, ceria dan bertaqwa. Selain itu rumah singgah al maun juga berupaya memenuhi kebutuhan anak berupa akses pendidikan sekolah. Dan saat ini rumah singgah al maun sudah mengakses ujian paket A bagi 4 orang anak jalanan, akses lapangan kerja di aura katering. Sementara kedepannya berencana membuka usaha yang bisa dikelola oleh anak dan orang tua sehingga mereka tidak perlu lagi berkaktivitas di 
jalan raya dan bisa fokus untuk dibantu oleh relawan mahasiswa UMB dan meneruskan pendidikan dan masa tumbuh kesejahteraan sosial UNIB yang di isi dengan kembang yang lebih kondusif.

Kegiatan yang baru dilaksanakan oleh rumah singgah al maun dalam memperingati hari anak nasional tahun 2019 adalah "Temu Penguatan Anak dan Keluarga (TEPAK) Rekreatif dengan tema "Penguatan Pengasuhan Anak Dalam keluarga). Kegiatan rekreatif ini dilakukan dengan nonton bareng (Nobar) film edukasi pengasuhan Islami Iqro My Universe yang khusus tayang ulang atas permintaan rumah singgah al maun bersama 55 anak dan orang tua binaan yang terdiri dari anak jalanan, anak yatim dan anak dari keluarga tidak mampu.

Relawan Al maun dari pekerja anak dinas sosial kota bengkulu TEPAK Rekreatif ini bertujuan untuk melekatkan kembali relasi anak dan orang tua supaya saling terbuka, mendukung dan menerima anak dengan semua permasalahannya. Model edukasi rekreatif ini dipilih agar orangtua dan anak bisa bergembira bersama sehingga pesan-pesan yang disampaikan dapat diterima dan dipahami karena orang tua dan anak sudah mengalami hal-hal yang berat dalam hidupnya, sehingga harus memilih model edukasi yang tepat.

\section{Penutup}

Rumah singgah al maun setiap hari jumat ada agenda rutin setiap sore yang 


\section{Pustaka Acuan}

Agung Wahyono\& siti Rahayu, 1993, Tinjauan Tentang Peradilan Anak di Indonesia, Jakarta, Sinar Garfika.

Anton F.Susanto, 2015 Penelitian Hukum

Transformatif Partisipatoris, Setara

Press Malang

Anisa Indrayani, 2011 Pendidikan Anak

Dalam Keluarga Sebagai Bentuk

Perlindungan Anak Dalam Perspektif

Al-Qur'an Jurnal MusawaISSN: 1412-

3460 E-ISSN: 2503-4596,Vol.10, No.2,

Juli 2011 hal 184 ( Terakreditasi

Mentri Riset, Teknologi dan

Pendidikan Republik Indonesia Nomor

2/E/KPT/2015

Betra Sarianti, 2015 Perlindungan Anak Berhadapan Dengan Hukum Diantara Harapan dan Hambatan Jurnal Ilmiah Kutei ISSN 1412-9639 edisi 28 April 2015

Mardani 2016, Hukum Keluarga Islam di Indonesia Prenamedia Group Jakarta

Muladi \& Barda Nawawi, 1998 Teori-teori dan Kebijakan Pidana. Bandung, P.T Alumni.

M. Nasir Djamil, Anak Bukan Untuk Dihukum, Sinar Grafika, Jakarta, 2013,

Peter Mahmud Marzuki, 2005. Penelitian

Hukum, Jakarta Kencana, Jakarta https://kurniawanramsen.blogspot.com/ 2013/06/definisi-anak-terlantar.html

\section{Peraturan Perundang-undangan}

Undang Undang Nomor 4 Tahun 1979 tentang Kesejahteraan Anak

Kitab Undang-Undang Hukum Perdata 